\title{
Marital Violence and Employed Women's Contribution to Sustainable Development
}

\author{
**Etuk, Grace R. (Ph.D), Ojua, Takim Asu.(Ph.D), Iyam,Ukam I.(Ph.D \\ Candidate) \\ Department of Sociology, University of Calabar, Calabar, Cross River State. Nigeria \\ Department of Sociology, University of Calabar, Nigeria \\ Department of Sociology, University of Ibadan, Nigeria
}

\begin{abstract}
Women have always been part and parcel of the struggle to develop society. However, many times issues in this regard are portrayed as though they have been inactive. Evidence from scholarly studies have shown that the problem with women as regards societal development has not been lack of participation, but rather set backs in their participation arising from unfavourable and sometimes violatory social and cultural practices like marital violence. Because of such set backs, many women like the employed ones, who occupy positions where they disposed to contributing to societal development hardly create meaningful impact. This paper showcases the extent of damage a practice like marital violence can cause to the efforts and abilities of women as actors in sustainable societal developments, offering suggestions for possible change.
\end{abstract}

\section{Introduction}

Achieving sustainable development is top in the priorities of many societies. This has given rise to these societies adopting among other strategies, inclusion of women in all spheres of social life to facilitate their participation in the scheme of events directed at making the quest for sustainable development fruitful. One area of social life that has become open to women's involvement is the paid employment sector. In this sector, together with men, women provide the labour force/human resources needed to set sustainable development in motion. However, for the efforts of women in this sector to add value to sustainable development, society needs to remove from their way hurdles like marital violence, which plagues them just like other women. Marital violence as it affects employed women cannot be ignored, considering that it jeopardizes women's wellbeing and frustrates their God-given abilities. If left unaddressed, this problem can thwart employed women's effort and consequently stall the process of sustainable development

\section{Marital Violence: Women's Experience.}

Around the globe today, women are subjected to diverse negative treatments, most of which jeopardize their physical and mental wellbeing. These negative treatments, commonly described as violence against women, occur in different forms and degrees, and vary with different social and cultural contexts. One of such forms of violence is the type meted out on them by their spouses or partners. Marital violence or domestic violence as it is commonly described refers to situations of strong disagreement or conflict between partners in marriage and similar relationships, which often results in the infliction of pain or harm on one of the partners by the other. Davis (1994) describes it as a variety of actions that occur in relationships, adding that the term is used narrowly to cover incidents of physical attack when it may take the form of violations in forms like punching, choking, stabbing, throwing boiling water or acid, and setting on fire, the result of which can range from bruising to killing.

Men can be as much the victims of marital violence as women. However, reports on the problem reveal that the most vulnerable parties are women. Comprehensive and systematic studies on the problem of marital violence have been, and are still being undertaken in different societies by scholars and researchers and the results have always been that women are usually the victims. For instance, the United States Population Reference Bureau (2002) in its reports on gender-based violence stated that "domestic violence is typically directed at women and girls". Thus, Davis (1994) pointed out that women are the usual victims of domestic violence while men are the perpetrators. Also, Ganny (1996) observed that one in three marriages experiences physical violence at some point and women are usually the victims. Similarly, Burns, Lovich, Maxwell and Shapiro (1997) stated that everyday, women are slapped, kicked, beaten, humiliated, threatened, sexually abused and even murdered by their partners. Chukwuma, Osakwe, Ekpenyong and Imona (2002) thus stressed that the family is a site where apart from love and care, a lot of oppression, violence and exploitation also occur and the victims are often women. 
Barnett and Laviolette (1993) reported that of spousal violent crimes, 91 percent are attacks on women by their husbands or ex-husbands, adding that reports from the United States Federal Bureau of Investigation (FBI) show that males perpetrated 5.6 million violent attacks on their female partners between 1979 and 1987. They observed further that in 1983, records from the Police in Santa Barbara California, shows that 86 percent of victims of domestic disturbances were women, adding that between 1973 and 1982, women constituted as much as 94 percent of victims of marital violence in United States.

Additionally, the United States National crime victimization survey reported in Brown, Dubau and Mckeon (1997) that women are about six times more likely than men to experience violence committed by someone intimate, adding that in over 90 percent of cases of domestic violence between 1987 and 1991 , the victim was female. In addition, Brown, et al, (1997) reported that four out of every American woman is likely to become a victim of domestic violence, noting that one-third of these violent acts against women are committed by men who claim to love them. They further noted that reports from the American Medical Association show that husbands and boyfriends assault as many as four million women every year.

According to Barnett and Laviolette (1993), by mid 1980s, marital violence had reached such epidemic proportions that the United States Centre for Disease Control began to treat spouse abuse like any other epidemic. This is evident in their report that in the United States, women suffer 2,100 injuries annually as a result of marital violence, and make about 1,453,437 medical visits every year to treat injuries resulting from spousal assaults. Furthermore, Roberts (1996) reported that the United States Crime Survey Data estimated that the number of visits by women for medical care resulting from domestic violence stands as follows; 28,700 visits to a hospital emergency room, 39,000 - visits to physicians' offices, 21,000- in patient hospitalization, and 99,800 days of hospitalization.

Marital violence is a problem not limited to women of particular social backgrounds. Okolo (2004) observed that it occurs across societies, across social classes and religion, and could be experienced by any woman rich, poor, black, white, educated, uneducated, rural or urban dweller. Brown et al (1997) thus commented that women who are physically strong, emotionally together, financially successful, socially accepted and even spiritually ahead of most other women fall into the trap of marital violence just like less healthy women. Similarly, Davis (1994) noted that battered women come from all races, all socioeconomic classes, from towns and villages, housewives and wage earners, young and old. Specifically, reports from the United States Population Reference Bureau (2002) on gender-based violence in 1998 show that two to four million women of all races and classes are beaten every year. Roberts (1996) however noted that although marital violence is experienced by women of all social classes, religions, races and ethnic groups, the problem is more visible in the lower class or among the lowest income group.

Marital violence as it affects women can take different forms. Okolo (2004) observed that it includes but is not limited to the following; direct physical attack or beating, which may or may not lead to physical injuries, the use of abusive or derogatory language on them, and forceful sexual intercourse The United State Population Reference Bureau reported that marital violence as typically directed against women and girls may include battering, burning, emotional blackmail, mockery or ridicule, threats of abandonment, confinement to the home and withholding of money and other family support. In the words of Davis (1994), it may take the form of physical and sexual violation as well as psychological or mental violence, which can consist of repeated verbal abuse, harassment, confinement, deprivation of physical, financial and personal resources, limited contact with family members and friends. According to Browne (1987), physical abuse reported by women range from being slapped, punched with a fist, kicked or hurled bodily or being chocked, smothered or bitten. Furthermore, Browne noted that women reported cases of marital violence in which they were beaten with an object, threatened or injured with a weapon, scalded with hot liquid, held under water or sexually assaulted.

\section{Sustainable Development: Employed Women's Role}

Sustainable development is the type of development that caters for the needs of both the present and the future. The term was first introduced in the 1987 Brundtland report commissioned by United Nations (Giddens, 2006). According to Giddens, the commission considered sustainable development to mean meeting the needs of the present, without compromising the ability of the future generation to meet their own needs. Similarly, the Nigerian Environment Study/Action Team (1993) defined it as development that seeks to meet the needs and aspirations of the present without compromising those of the future. It is about improving the quality of life of the present generation without comprising the needs of the future generation (Nosike 1996)

In the quest to achieve sustainable societal development, employed women just like their male counterparts play roles which are significant enough not to be ignored. The possibility of making sustainable development itself a reality rests largely on such key issues like popular participation, collective autonomy as well as equity and distributive justice, which according to the Nigerian environment study/action team (1993) all constitute key elements of sustainable development. The United Nations Conference on Environment and Development (UNCED) in 1992 acknowledged among other issues concerning women (including the employed 
ones), their peculiar roles in development. Sharing this school of thought, advocates of the Human Resources Approach to Women and Development proposed that women have both reproductive and productive roles in development (Synder and Tadesse, 1995). The role of women generally and employed women in particular with regards to sustainable development is therefore not in contest. Unlike other women, employed women's role in sustainable development is unique and extended to the extent that apart from functioning in the same capacities as other women towards facilitating different dimension of development, they in addition provide the female quota of the human resources required to both initiate and sustain development.

Human resource in form of organized labour force is a major requirement for industrialization (Sills, 1968), which itself is a key dimension of development. Sustainable development cannot be attained only by the effective utilization of available natural resources. Besides natural resources, there is also need for the utilization of human resources. Without human resources, even natural resources will be meaningless to sustainable development. Stressing the relevance of human resources to development, Essien (2005) stated that it takes only humans to plot the direction of development, and to harness and deploy other resources such as capital and technology necessary for the task. Essien noted further that it is human resources that supply the entrepreneurship or know-how needed for creating new visions, as well as provide different grades of labour needed for the production and distribution of goods and services.

In their various capacities in the labour market, employed women function along side men to provide the human resources needed to steer the wheel of sustainable development from the labour market angle. One cannot begin to imagine how the labour force would have been, and even how much would have been achieved from this angle in terms of sustainable development, if women were kept out of the picture. They are diversely positioned in different capacities as civil servants, public servants, employees of different private, corporate as well as non governmental organizations, working hand in hand and side by side with men to ensure that development is achieved and sustained. Without doubt therefore, compared to other women, employed women occupy a primary and sensitive position as far as sustainable societal development is concerned.

\section{Sustainable Development and the Challenge of Marital Violence: The Case Employed Women}

The several evidences cited so far leave no doubt regarding the role of employed women in sustainable development. Therefore given the necessary support, with a view to maximizing their contributions, society's dream of achieving this crucial goal will more than ever, be closer to reality. But then a question arises; what happens if some or most of these (employed) women, like other females, are trapped in marital violence? What possible ripple effect will this have on sustainable development? One might also ask; can employed women possibly face marital violence, considering that a good number of them are likely to be educated, financially independent and enlightened? The answer is not far fetched. Employed women are as much the victims of marital violence as any other set of women. As previously observed, violence against women (including the marital forms) affects women of all countries, classes, income groups as well as races. This means that employed women are not left out. For instance, a survey in Cross Rivers State, South-South Nigeria, by Okolo (2006) on marital violence reveals that of 504 employed women studied; only $8.8 \%$ of them indicated they had not experienced any form of marital violence. The remaining $91.2 \%$ indicated they face one form of marital violence or the other. To what extent then can marital violence impinge on employed women's contribution towards sustainable development?

Marital violence exposes women to physical injuries and pain. Women who are exposed to marital violence are usually associated with wounds and bruises, broken bones, black eyes, and swollen faces. These, Okolo (2004) noted, might further result to other health problems and may last very long with the woman involved. Bradley (1997) observed that marital violence could even end a woman in death, as one blow is enough to kill a person.

If employed women sustain physical injuries or breakdown in health due to marital violence, as the case often is, the ripple effect on sustainable development will be huge. It is said that health is wealth. It can only take a healthy person to be part of development activities. In other words, it is only when employed women, just like other individuals are in good health conditions that they can participate as human capital in any venture geared towards sustainable development. However, if they are down with injury, pain or other health disorders, how can they effectively participate in sustainable development? Naturally, if they experience any negative health condition, they have to stay off work and spend sometime at home or even at the hospital in order to recover. A report by the Australian Domestic and Family Violence Clearing House shows that they may even be prevented from coming to work by having their cloths hidden or physically stopped from leaving home (http://www.au.org.au.pdf/fact-sheet-domestic-violence-ADFVC-pdf). Staying off work for some time to recover from health problems or even keep court appointments resulting from marital violence would mean a short fall in the human resources at work place to facilitate and sustain development. This would also mean that some tasks at work would either take a longer time to be accomplished due to this short fall in personnel, or even wait till they resume work. Such delays are unarguably a set back on sustainable development. 
Apart from physical health challenges, marital violence results in emotional and mental health problems in women. For the employed ones, this will adversely affect their role in sustainable development. A stable and balanced emotional state constitutes a necessary resource for effective participation in development. Marital violence robs employed women of this resource. Davis (1994) observed that women who are faced with frequent violence in their homes have significantly higher levels of emotional disorders like anxiety, depression, and somatic complaints than women who do not suffer such abuse. Bradley (1997) also stressed that loss of self confidence and feelings of helplessness may even set in for such women. Occasionally, people complain of "unpleasantness" on the part of some employed women in their interactions at work. Certainly, such attitudes at work will not augur well with both development and its sustenance. However, it is important to note that such unpleasant attitudes are reflections of unhealthy emotional states in such women, which results sometimes from violence inflicted on them by their spouses at home.

According to Brown, Dubau and Mckeon (1997), as a way of coping with emotional problems resulting from marital violence, some women resort to alcohol and drugs in order to overcome their emotional states. The implication of this for employed women is that as players in sustainable development, their role will be compromised. Under the influence of drugs, no one can function effectively. Considering that some of the drugs/alcohol would complicate rather than solve their emotional problems further puts their role as human resources in sustainable development at risk. Besides making such women ineffective in their jobs, drug/alcohol can make them a threat to other actors in, as well as the entire process of sustainable development. For instance, if such women function as teachers, not only are they likely not to teach well, they may also bully their pupils. Where would this leave the pupils who themselves give development a future and sustainability?

Sustainable development can further be jeopardized if there is a hemorrhaging of employed women's motivations because of violence at home. Burns et al (1997) reports that violence in the home results to lack of motivation and lack of a sense of self worth in women. Increased productivity at workplace which is a key element of sustainable development is largely a function of adequate motivation in employees. Therefore, if these women begin to experience a drop in their levels of motivation due to domestic violence, productivity will certainly drop. The long term consequence will be a drag in the entire process of sustainable development.

Lastly, in extreme cases of violence at home, death could occur due to its attendant health complications, or suicide. It is reported that violence is a leading contributor to death in women aged 15-44, being a greater contributor than high blood pressure, smoking and obesity. (http://www.auf.org.au.pdf/factsheet-domestic-violence-ADFVC-pdf). The overall implication of this will be out right loss of human resources, which is a minus for sustainable development

\section{Suggestions for Change}

By virtue of the peculiarity of their roles, employed women deserve to be given every available and possible support to ensure that their contributions to sustainable development are optimized. To save them and indeed other women from the scare of marital violence, the following strategies will be useful.

- Awareness creation: To help reduce wide spread ignorance and consequently the problem itself, particularly as it affects sustainable development. This can be achieved through educational and public enlightenment programmes championed and or supported by governmental and non governmental agencies, women organizations, the media and international agencies.

- Legal frameworks: Research reveals that culprits of martial violence are usually not severely punished Okolo (2004). Existing legal frameworks should be reviewed and tightened to ensure that cases are carefully examined and where any one is found guilty, severe punishments should be noted meted out instead of few months imprisonments with fine options as Okolo observed has been the case. Severe punishments would go a long way to deter individuals from taking marital disharmony to extremes. Okolo (2004) further emphasized that law enforcement agents often dismiss reports of spousal abuse, telling the victims to settle it at home since it is a " domestic affair" Legal processes in this regard should be strengthened to guarantee speedy actions and supports rather than dismiss them as 'domestic affair'.

- Support and counseling services: Women groups, non-governmental organizations, international and even governmental agencies can further curb this problem by setting up support and counseling centres. Such support centres will serve to provide avenues for employed women to get together with other women facing the same problems to freely discuss the issue with a view to finding solutions. This is very important because research shows that most women who face marital violence hardly disclose their experiences. Such support centres can also serve to provide professional counseling on how to avoid, cope with or overcome spousal violence

\section{Conclusion}

Genesis chapter 2 verse 18 in the Bible reads "it is not good for the man to be alone; I will make a helper suitable for him". This statement portrays the Biblical account of God's intention for creating women; to 
help men. Going by this view, in every sphere of life, including sustainable development, the contributions and support of women generally are somewhat indispensable. For employed women, their contributions in sustainable development are even more peculiar given their function as human resources in the labour market, which is a key area that serves as a driving force for sustainable development. Achieving this however depends largely on the level of support they are given to perform this function, as well as the preparedness of society to remove all forms socially and culturally created barriers that slow their abilities. Marital violence has been identified as one of such barriers. If this problem is tackled or at least minimized, then employed women will together make a formidable resource in sustainable societal development.

\section{References}

[1]. Barnett, O. W. and Laviolette, A. D. (1993). It could happen to any one: Why battered women stay. London: Sage Publication.

[2]. Brown, L., Dubau, F, and Mckeon, M. Y. D (1997). Stop domestic violence: An action plan for saving lives. New York: St. Martin's Griffin.

[3]. Browne, A. (1987). When battered women kill. New York: Free Press.

[4]. Burns, A. A., Lovich, R., Maxwell, Y and Shapiro, K. (1997). Where women have no doctor: A health guide for women. California: Macmillan.

[5]. Chukwuma, J. E., Osakwe, B., Ekpenyong, U. and Imona, M. (2002).No save haven: Reports of attacks on women in Nigeria December 2000-November 2002 Lagos. Mbeyi and Associates.

[6]. Davis, M. (1994). Women and violence: Realities and responses worldwide. New York: Zed books.

[7]. Essien, E. E. (2005) "Empowering women for development: A business perspective". In I. V. O. Modo (ed). Sustainable development in Africa-A book of readings. Uyo. Cultural research publishers.

[8]. Ganny, M. (1996). "Domestic violence: The case of wife abuse and its effects on women's contribution to national development". In Y. Oruwari (ed). Women, development and the Nigerian environment. Ibadan, Vantage publishers.

[9]. Giddens, A. (2006) Sociology. Cambridge: Polity Press.

[10]. Nigerian Environmental Study/Action (1993) Nigeria: The Challenge of Sustainable Development. Ibadan.

[11]. Nosike, A, N. (1996). Violence against women and sustainable development: A contemporary perspective. In Y. Oruwari (ed) Women, development and the Nigerian environment. (pp 53-62) Ibadan: Vantage Publishers.

[12]. Okolo, G. U. (2004). Violence against women. Calabar: Baye communications.

[13]. Okolo, G. U. (2006) Marital violence and labour productivity of employed women: A case study of cross river state, Nigeria. unpunished Doctoral thesis. Department of Sociology, University of Calabar, Calabar, Nigeria.

[14]. Roberts, A. R. (1996). “Myths and realities regarding battered women” In A. R. Roberts (ed) Helping battered women new perspectives and remedies. (pp 3-12 ) New York: Oxford University Press.

[15]. Sills, D. (1968). International encyclopedia of social sciences. Vol. 7. New York: The Macmillan company and the Free Press.

[16]. Synder, M.C. and Tadesse, M. (1995) African Women and Development. London Zed Books.

[17]. United Nations Conference on Environment and Development (UNCED) (2002) Declaration on Environment and Development.

[18]. United States Population References Bureau, (PRB) (April 2002). Conveying concerns: Women report on gender based violence Washington, D.C. PRB 